\title{
Chronic Exposure to Water-Pipe Smoke Induces Alveolar Enlargement, DNA Damage and Impairment of Lung Function
}

\author{
Abderrahim Nemmar ${ }^{\mathrm{a}}$ Suhail Al-Salam ${ }^{\mathrm{b}}$ Priya Yuvaraju ${ }^{\mathrm{a}}$ Sumaya Beegam ${ }^{\mathrm{a}}$ \\ Javed Yasinc Badreldin $\mathrm{H}$. Alid \\ aDepartment of Physiology, College of Medicine and Health Sciences, United Arab Emirates University, \\ Al Ain, UAE; 'Department of Pathology, College of Medicine and Health Sciences, United Arab Emirates \\ University, Al Ain, UAE; 'Department of Internal Medicine, College of Medicine and Health Sciences, \\ United Arab Emirates University, Al Ain, UAE; 'Department of Pharmacology and Clinical Pharmacy, \\ College of Medicine \& Health Sciences, Sultan Qaboos University, Al-Khod, Sultanate of Oman
}

\section{Key Words}

Water-pipe smoking - Nose-only exposure Chronic exposure Lung function • Oxidative stress $•$ Inflammation $\cdot$ DNA damage $\cdot$ Alveolar injury

\begin{abstract}
Background/Aim: Epidemiological evidence indicates that water-pipe smoking (WPS) adversely affects the respiratory system. However, the mechanisms underlying its effects are not well understood. Recent experimental studies reported the occurrence of lung inflammation and oxidative stress following acute and subacute exposure to WPS. Here, we wanted to verify the extent of inflammation and oxidative stress in mice chronically-exposed to WPS and to evaluate, for the first time, its effect on alveolar injury and DNA damage and their association with impairment of lung function. Methods: Mice were nose-only exposed to mainstream WPS (30 min/day; 5 days/week for 6 consecutive months). Control mice were exposed using the same protocol to atmospheric air only. At the end of the exposure period, several respiratory parameters were assessed. Results: In bronchoalveolar lavage fluid, WPS increased neutrophil and lymphocyte numbers, lactate dehydrogenase, myeloperoxidase and matrix metallopeptidase 9 activities, as well as several proinflammatory cytokines. In lung tissue, lipid peroxidation, reactive oxygen species, superoxide dismutase activity and reduced glutathione were all increased by WPS exposure. Along with oxidative stress, WPS exposure significantly increased lung DNA damage index. Histologically the lungs of WPS-exposed mice had foci of mixed inflammatory cells infiltration in the interalveolar interstitium which consisted of neutrophils, lymphocytes and macrophages. Interestingly, we found dilated alveolar spaces and alveolar ducts with damaged interalveolar septae, and impairment of lung function following WPS exposure. Conclusion: We show the persistence of lung inflammation and oxidative stress in mice chronically-exposed to WPS and demonstrate, for the first time, the occurrence of DNA damage and enlargement of alveolar spaces and ducts associated with impairment of lung function. Our findings provide novel mechanistic elucidation for the longterm effects of WPS on the respiratory system.




\section{Cellular Physiology Cell Physiol Biochem 2016;38:982-992 and Biochemistry Published online: March 04, $2016 \quad \begin{aligned} & \text { DOI: 10.1159/000443050 } \\ & \begin{array}{l}\text { (c) 2016 The Author(s). Published by S. Karger AG, Basel } \\ \text { www.karger.com/cpb }\end{array}\end{aligned}$ \\ Nemmar et al.: Chronic Respiratory Effects of Water-Pipe Smoking in Mice}

\section{Introduction}

Chronic obstructive pulmonary disease (COPD) is a leading global cause of mortality and chronic morbidity, and inhalation of tobacco smoke is the principal risk factor for the development of this disease [1]. Worldwide, tobacco use causes nearly 6 million deaths per year, and current trends suggest that tobacco use will cause more than 8 million deaths annually by 2030 [1]. Water-pipe smoking (WPS), hubble bubble, shisha, hookah or narghile is a form of tobacco use that has been practiced for centuries. WPS is prevalent in the Middle East and Asia, and is now growing in popularity in the West as well, especially among school and university students [2].

The tobacco used in WPS ("moasel") contains 30\% tobacco and 70\% honey or molasses. Most smoking sessions last 30 minutes; up to several hours [3]. In its most common form, during inhalation the smoke from the charcoal is drawn through the tobacco down the pipe and towards the water. After bubbling through the water, the cooled smoke surfaces and is pulled through the hose and inhaled by the smoker. In spite of a perception that the risk of WPS may be less than those of cigarettes, a recent report suggests that its harmful effects are similar or even more than those of cigarettes [4]. The highest prevalence of use of WPS is presently among adolescents and women $[5,6]$. There is evidence that those who are occasional or regular water-pipe smokers are more probably to become regular cigarette smokers, suggesting that WPS may be a potential gateway for regular cigarette use [7].

Although the effect of cigarette smoking (CS) on the respiratory system has been systematically investigated, studies on the adverse pulmonary effects of WPS are relatively limited [8]. Acute exposure to WPS has been associated with a decrease in peak expiratory flow rate (PEFR), forced expiratory flow between 25 to $75 \%$ of forced vital capacity $\left(\mathrm{FEF}_{25-75 \%}\right)$, whereas chronic exposure cause a decrease in the forced expiratory volume in one second $\left(\mathrm{FEV}_{1}\right)$ and forced vital capacity $(\mathrm{FVC}), \mathrm{FEV}_{1} / \mathrm{FVC}$ and $\mathrm{FEF}_{25-75 \%}[9,10]$. Moreover, association between WPS and COPD has been reported after adjusting for possible confounders such as age and CS $[11,12]$.

Experimental studies on the respiratory effects of WPS are very scarce. Recent studies reported that acute exposure to WPS using whole body or nose-only WPS exposure systems caused an increase in proinflammatory cytokines and markers of oxidative stress $[13,14]$. We recently demonstrated that exposure to WPS for one month increased airway resistance, inflammation, and oxidative stress [15]. However, no experimental data are available on the chronic pulmonary effect of WPS exposure. Such study is essential because it would provide biological plausibility for the epidemiological and clinical studies linking WPS and chronic adverse respiratory effects (e.g. COPD) [11, 12].

Therefore, in the present study, we sought to verify the persistence of pulmonary inflammation and oxidative stress in mice chronically-exposed (six months) to WPS and to assess, for the first time, its effect on alveolar injury and DNA damage and their association with impairment of lung function.

\section{Materials and Methods}

\section{Animals and treatments}

This project was reviewed and approved (A-31-13) by the Institutional Review Board of the United Arab Emirates University, College of Medicine and Health Sciences, and experiments were performed in accordance with protocols approved by the Institutional Animal Care and Research Advisory Committee.

WPS exposure

Male C57BL/6 mice ( 20 g, 8-weeks old) were obtained from Taconic Farms Inc. (Germantown, NY, USA) were housed in a conventional animal house and maintained on a 12-hour light-dark cycle. The animals were placed in cages and supplied with pelleted food and water ad libitum. Following 1 week of acclimatization, animals were randomly divided into air (control) and WPS-exposed groups. Mice were placed in soft restrainers and connected to the exposure tower [13, 15-18]. They were exposed to WPS 


\section{Cellular Physiology Cell Physiol Biochem 2016;38:982-992

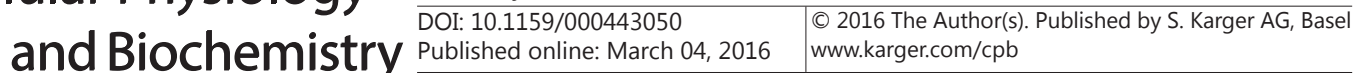 \\ Nemmar et al.: Chronic Respiratory Effects of Water-Pipe Smoking in Mice}

or air through their noses using a nose-only exposure system (InExpose System, Scireq, Canada). Animals were exposed to mainstream WPS generated by commercially available honey flavored "moasel" tobacco (Al Fakher, Ajman, UAE). The tobacco was lit with instant light charcoal disk (Star, $3.5 \mathrm{~cm}$ diameter and $1 \mathrm{~cm}$ width). A standard of one puff of 2-s duration was taken once a minute, followed by $58 \mathrm{~s}$ of fresh air at a rate of $6 \mathrm{ml} / \mathrm{s}$ was applied $[13,15,17,19,20]$. The duration of the session was $30 \mathrm{~min} /$ day and 5 days/week for 6 months (except during the days of Friday and Saturday each week). The 30-min duration of the exposure session was selected from a recently published study that has assessed the cardiorespiratory effects of WPS in human subjects [21]. At the end of the six-month exposure period, various respiratory parameters were evaluated.

\section{Collection and analysis of bronchoalveolar lavage fluid (BALF)}

The collection and analysis of BAL has been performed according to a previously described method [2225]. In brief, after WPS or air exposure, the mice were sacrificed with an overdose of sodium pentobarbital. The trachea was cannulated and lungs were lavaged three times with $0.7 \mathrm{ml}$ (a total volume of $2.1 \mathrm{ml}$ ) of sterile $\mathrm{NaCl} 0.9 \%$. The recovered fluid aliquots were pooled. No difference in the volume of collected fluid was observed between the different groups. BAL fluid was centrifuged $\left(1,000 \mathrm{gx} 10 \mathrm{~min}, 4^{\circ} \mathrm{C}\right)$. Cells were counted and the differentials were microscopically performed on cytocentrifuge preparations fixed in methanol and stained with Diff Quick (Dade, Brussels, Belgium). The supernatant was stored at $-80^{\circ} \mathrm{C}$ until further analysis.

Measurement of lactate dehydrogenase (LDH), myeloperoxidase (MPO), matrix metallopeptidase 9 (MMP9), tumour necrosis factor $\alpha$ (TNF $\alpha$ ), interleukin (IL)-6 and IL1 $\beta$ in BALF

The activity of LDH was measured using a commercially available kit from Roche (Basel, Switzerland) in blood chemistry analyzer (Roche COBAS, Switzerland). The concentrations of MPO, MMP9, TNF $\alpha$, IL-6 and IL1 $\beta$ were performed using ELISA kits (R \& D systems, Minneapolis, MN, USA).

\section{Histopathology}

In separate animals ( $\mathrm{n}=6$ in each group), the heart-lung block were excised and fixed in $6 \%$ paraformaldehyde at a constant hydrostatic pressure of $20-25 \mathrm{~cm}$ fluid column for 24 hours [26]. After dehydration and embedding in paraffin, sagittal sections were stained with H\&E to evaluate lung inflammation and airspace and alveolar duct enlargements. The diameter of alveolar spaces and ducts were measured in 10 randomly selected high power fields per slide, at $400 \mathrm{x}$ magnifications in blinded manner, by the histopathologist who participated in this project, using an Olympus DP71 camera and software (Olympus Corporation).

Measurements of lipid peroxidation (LPO), reactive oxygen species (ROS), superoxide dismutase (SOD) and GSH levels in lung tissue

In separate mice ( $\mathrm{n}=8$ in each group), following the exposure to WPS or air, animals were sacrificed by an overdose of sodium pentobarbital. Lung tissues from air-exposed control and WPS-exposed mice were collected and rinsed with ice-cold PBS ( $\mathrm{pH} 7.4$ ) before homogenization in $0.1 \mathrm{M}$ phosphate buffer $\mathrm{pH} 7.4$ containing $0.15 \mathrm{M} \mathrm{KCl}, 0.1 \mathrm{mM}$ EDTA and $0.1 \mathrm{mM}$ phenylmethylsulfonylfluoride at $4^{\circ} \mathrm{C}$. Homogenates were centrifuged for $10 \mathrm{~min}$ at $3000 \mathrm{xg}$ at $4^{\circ} \mathrm{C}$ to remove cellular debris, and supernatants were used for further analysis. Protein content was measured by Bradford's method as described before [13, 17].

NADPH-dependent membrane LPO was measured as thiobarbituric acid reactive substance using malonedialdehyde as standard (Sigma-Aldrich Fine Chemicals, St Louis, MO, USA) [13, 17].

Measurement of ROS: ROS were measured in the whole lung tissue homogenates which were obtained as described above using 2', 7'- Dichlorofluorescein diacetate (DCFDA; Molecular Probes, Eugene, OR, USA) as a fluorescent probe as described before [17]. The results were normalized as ROS produced per mg of protein.

Measurement of SOD activity: This was measured as the conversion of nitro blue tetrazolium (NBT) to NBT-diformazan according to the vendor's protocol (R \& D System, MN, USA). The extent of reduction in the appearance of NBT-formazan was used as a measure of SOD activity present in the experimental samples.

Measurement of GSH concentrations: This was carried out in control and WPS-exposed animals by standard procedures as described in previous publications $[13,17]$. 


\section{Cellular Physiology Cell Physiol Biochem 2016;38:982-992

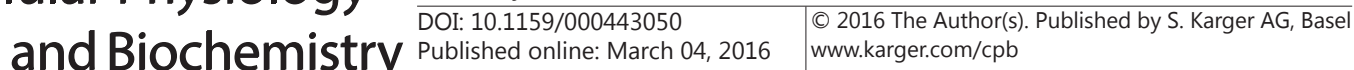 \\ Nemmar et al.: Chronic Respiratory Effects of Water-Pipe Smoking in Mice}

DNA damage assessment by COMET assay

In separate animals ( $\mathrm{n}=5$ in each group), immediately after the sacrifice, the lungs from air- and WPS-exposed mice were removed. The comet assay was used as previously described [27, 28], and the measurement of length of the DNA migration (i.e diameter of the nucleus plus migrated DNA) was calculated using the image analysis Axiovision 3.1 software (Carl Zeiss, Canada) [29].

Airway reactivity to methacholine

Airway hyperreactivity responses were measured using a forced oscillation technique (FlexiVent, SCIREQ, Montreal, Canada). Airway resistance (R) was assessed after increasing exposures to methacholine. Mice ( $\mathrm{n}=8$ in each group) were anesthetized with an intraperitoneal injection of pentobarbital $(70 \mathrm{mg} / \mathrm{kg})$. The trachea was exposed and an 18-gauge metal needle was inserted into the trachea. Mice were connected to a computer-controlled small animal ventilator and quasi-sinusoidally ventilated with a tidal volume of $10 \mathrm{ml} / \mathrm{kg}$ at a frequency of 150 breaths/min and a positive end-expiratory pressure of $2 \mathrm{~cm}_{2} \mathrm{O}$ to achieve a mean lung volume close to that during spontaneous breathing. After measurement of a baseline, each mouse was challenged with methacholine aerosol, generated with an in-line nebulizer and administered directly through the ventilator for $5 \mathrm{~s}$, with increasing concentrations $(0,0.625,2.5,10$ and $40 \mathrm{mg} / \mathrm{ml})$. $\mathrm{R}$ was measured using a "snapshot" protocol each $20 \mathrm{~s}$ for $2 \mathrm{~min}$. The mean of these five values was used for each methacholine concentration, unless the coefficient of determination of a measurement was smaller than 0.95 . For each mouse, $\mathrm{R}$ was plotted against methacholine concentration (from 0 to $40 \mathrm{mg} / \mathrm{ml}$ ) $[24,30]$.

\section{Statistics}

All statistical analyses were performed with GraphPad Prism Software version 5. To determine whether parameters were normally distributed, the KS normality test was applied. Normally distributed data were analyzed using the unpaired $t$-test (airway resistance, PMN, IL-1 1 , IL-6, alveolar space and duct diameters, ROS and DNA damage) for differences between groups. Non-normally distributed data (MPO, MMP9, TNFa, LPO, SOD and GSH) were analyzed using Mann Whitney test for differences between groups. All the data in figures were reported as mean \pm SEM. $P$ values $<0.05$ are considered significant.

\section{Results}

\section{Cell composition and numbers and LDH activity in BALF}

Compared to control group, six month nose-only WPS exposure caused an insignifiant increase in macrophage numbers (Fig. 1A). However, the numbers of neutrophil were significantly increased in WPS-exposed group compared with air-exposed one $(\mathrm{P}<0.001$; Fig. 1B). Likewise, the numbers of lymphocyte were significantly increased in WPS-exposed group ( $<<0.005$; Fig. 1C).

LDH activity was significantly increased in WPS-exposed mice compared to those exposed to air ( $\mathrm{P}<0.001$; Fig. 1D).

\section{MPO and MMP9 concentrations in BALF}

MPO concentration in BALF was significantly increased $(P<0.0005)$ following chronic nose-only WPS exposure compared with air-exposed mice (Fig. 2A). Similarly, six month nose-only WPS exposure caused a significant augmentation of MMP9 concentration in BALF $(\mathrm{P}=0.001$; Fig. 2B).

TNF $\alpha, I L-6$ and IL1 $\beta$ concentrations in BALF

TNF $\alpha$ concentration in BAL fluid was significantly increased $(\mathrm{P}<0.0005)$ following noseonly WPS exposure compared to air-exposed mice (Fig. 3A). Likewise, IL-6 concentration was also increased $(\mathrm{P}<0.05)$ after nose-only WPS exposure (Fig. 3B) compared to air-exposed mice. The concentrations of IL1 $\beta$ observed in BALF following chronic exposure to WPS was significantly enhanced $(\mathrm{P}=0.01)$ compared with air exposed-group (Fig. $3 \mathrm{C})$. 
Fig. 1. Number of macrophages (A), polymorphonuclear neutrophils (PMN, B) and lymphocytes (C) and lactate d e hy dro ge nase $(\mathrm{LDH}, \mathrm{D})$ in bronchoalveolar lavage fluid (BALF) at the end of the six-month exposure period to air (control) or water pipe smoking (WPS). Data are mean \pm SEM (n = 9-10).
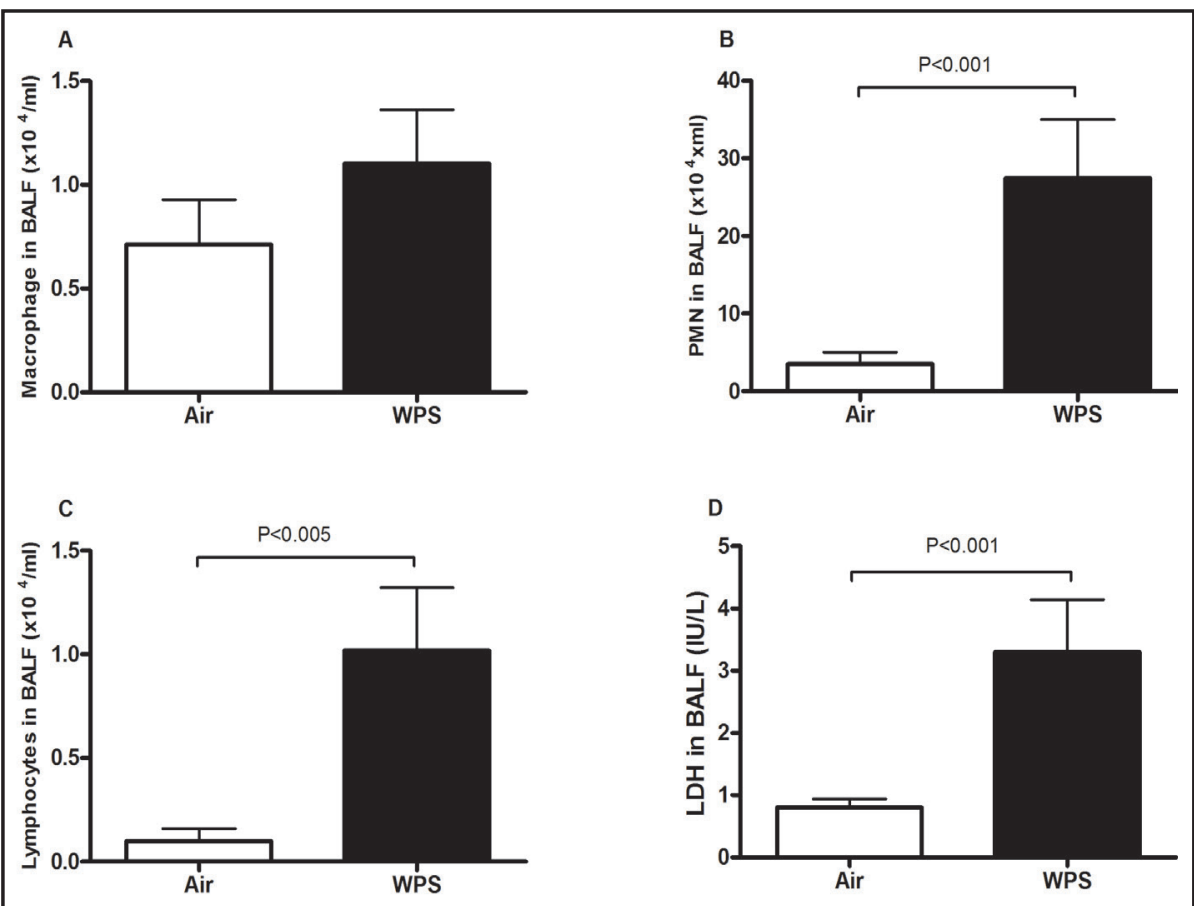

Fig. 2. Myeloperoxidase (MPO, A) and matrix metallopeptidase 9 (MMP9, B) in bronchoalveolar lavage fluid (BALF) at the end of the six-month exposure period to air (control) or water pipe smoking (WPS). Data are mean \pm SEM $(n=8)$.
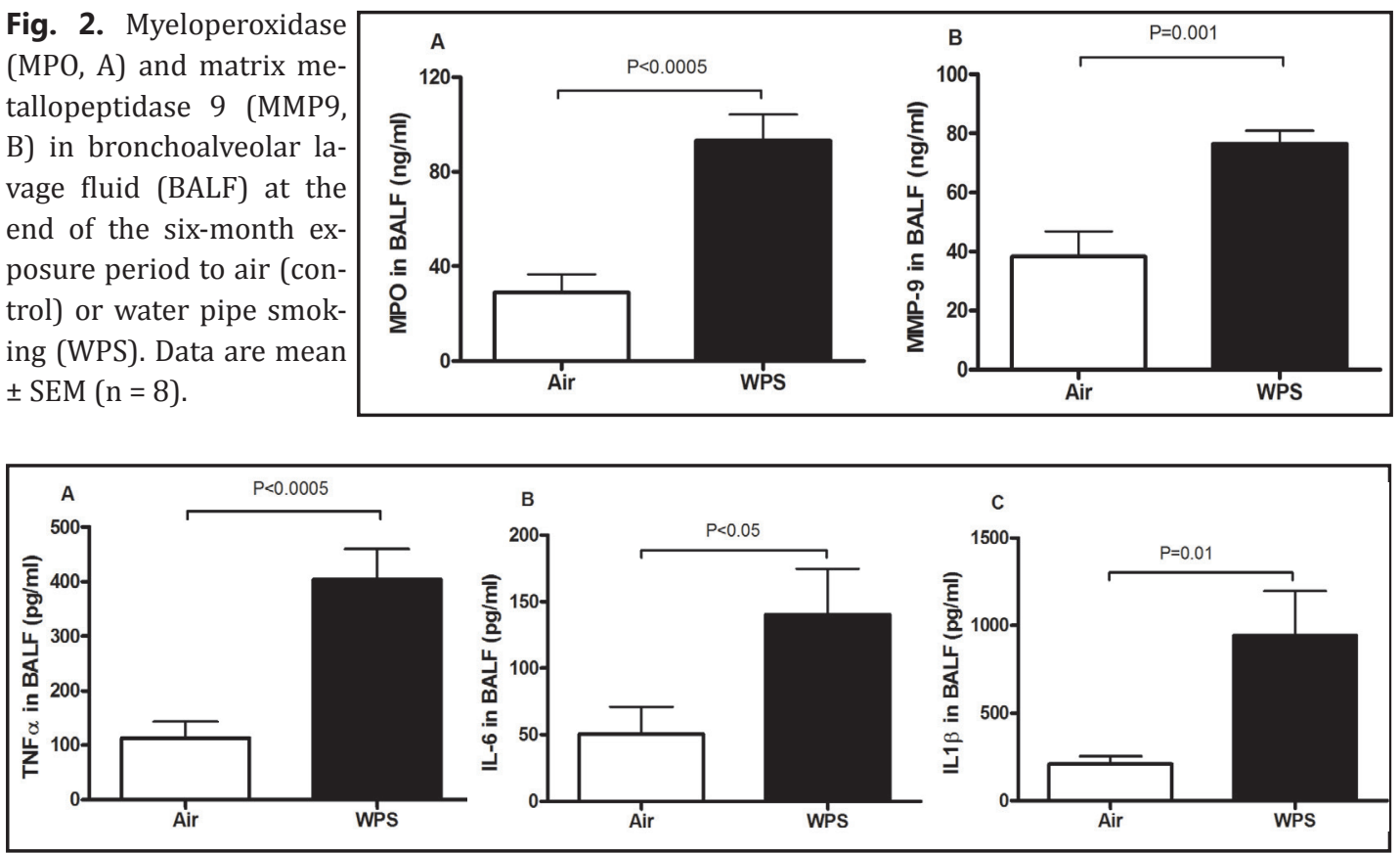

Fig. 3. Tumour necrosis factor $\alpha(\mathrm{TNF} \alpha, \mathrm{A})$, interleukin 6 (IL-6, B) and interleukin $1 \beta$ (IL1 $\beta$ ) in bronchoalveolar lavage fluid (BALF) at the end of the six-month exposure period to air (control) or water pipe smoking (WPS). Data are mean \pm SEM $(n=8)$.

\section{Lung histopathology}

Sections of lung from air-exposed mice showed a normal appearance with uniform alveolar spaces and alveolar ducts under light microscopy (Fig. 4A-D). In control group, the mean diameter of alveolar spaces was $37.1 \pm 2.1 \mu \mathrm{m}$, and that of alveolar duct was $82.3 \pm$ $3.0 \mu \mathrm{m}$ (Fig. 5). WPS-exposed group (Fig. 4E-L) showed dilated alveolar spaces and alveolar ducts with damaged interalveolar septae. Compared with air-exposed group, there was a 


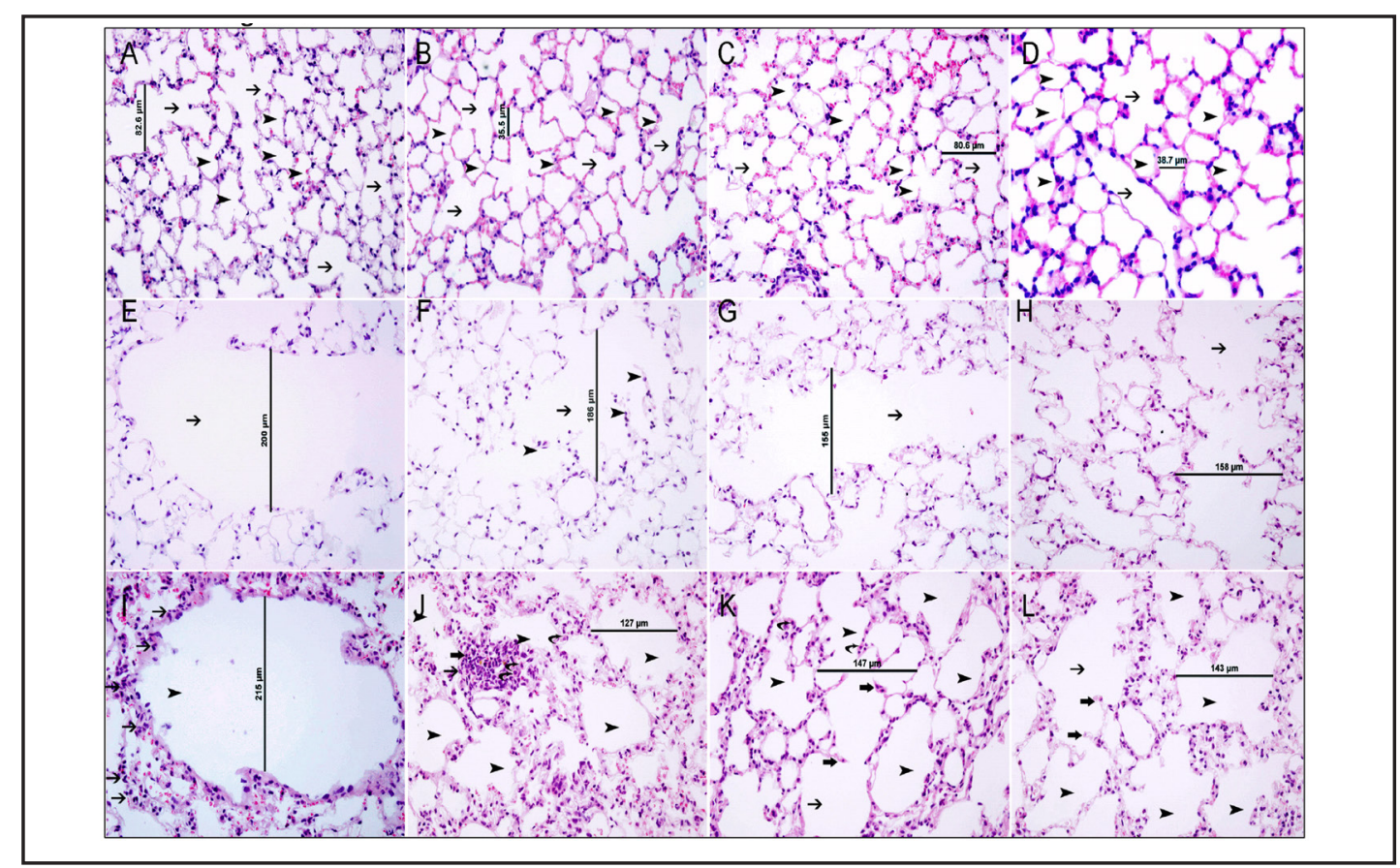

Fig. 4. Representative illustrations of a lung section stained with $H \& E$ in control (A-D) and water pipe smoke (WPS, E-L)-exposed mice at the end of six months exposure period. (A, B, C and D show uniform alveolar spaces (arrow head) and alveolar ducts (thin arrow). (E, F,G and H show dilated alveolar ducts (thin arrow) with damaged interalveolar septae (arrow head). I and J show dilated alveolar spaces (arrow head), with foci of mixed inflammatory cells infiltration of the interalveolar interstitium consisting of neutrophils polymorphs mainly (thin arrow), lymphocytes (thick arrow) and macrophages (curved arrow). K and L show dilated alveolar duct (thin arrow), and alveolar spaces (arrow head) with damaged interalveolar septae (thick arrow).

Fig. 5. Mean alveolar space diameter (A) and alveolar duct diameter (B) at the end of the six-month exposure period to air (control) or water pipe smoking (WPS). The diameter of alveolar spaces and ducts were measured in 10 randomly selected high power fields per slide, at $400 \mathrm{x}$ magnifications

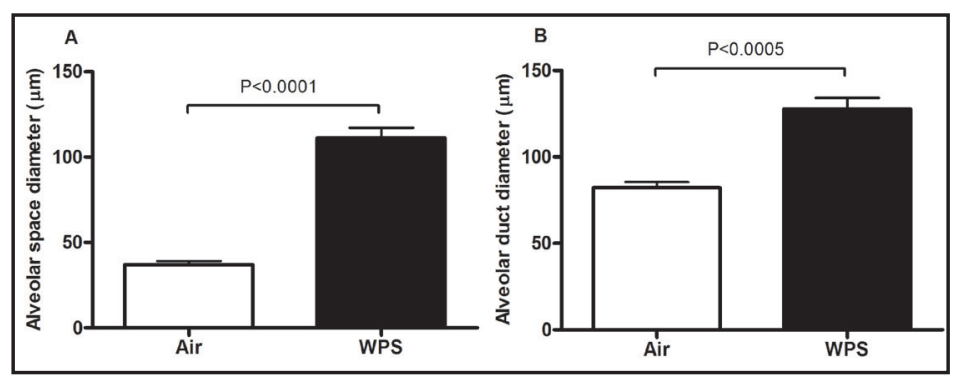
in blinded manner using an Olympus DP71 camera and software Data are mean \pm SEM (n $=6)$.

significant increase in alveolar space diameter in WPS group $(111.2 \pm 5.9 \mu \mathrm{m} ; \mathrm{P}<0.0001$; Fig. 5A) with foci of mixed inflammatory cells infiltration in the interalveolar interstitium consisting of mainly neutrophils and macrophages with a few lymphocytes. Similarly, WPS exposure caused a significant dilatation alveolar ducts (127.7 $\pm 6.4 \mu \mathrm{m} ; \mathrm{P}<0.0005$; Fig. 5B).

\section{LPO, ROS, SOD and GSH in lung tissue}

Figure 6 illustrates the effect of six month nose-only WPS or air exposure on markers of oxidative stress in lung tissue. Six months nose-only WPS exposure induced a significant increase in LPO (P < 0.0001; Fig. 6A) and ROS (P<0.0005; Fig. 6B) compared with air exposed group. The antioxidants SOD and GSH in lung were both significantly increased $(\mathrm{P}<0.0001)$ following the chronic exposure to WPS compared to air-exposed group.

\section{KARGER}


Fig. 6. Lipid peroxidation (LPO, A), reactive oxygen species (ROS, B), superoxide dismutase (SOD, C) and glutathione (GSH, D) levels in lung tissues at the end of the six-month exposure period to air (control) or water pipe smoking (WPS). Data are mean \pm SD ( $\mathrm{n}=8)$.
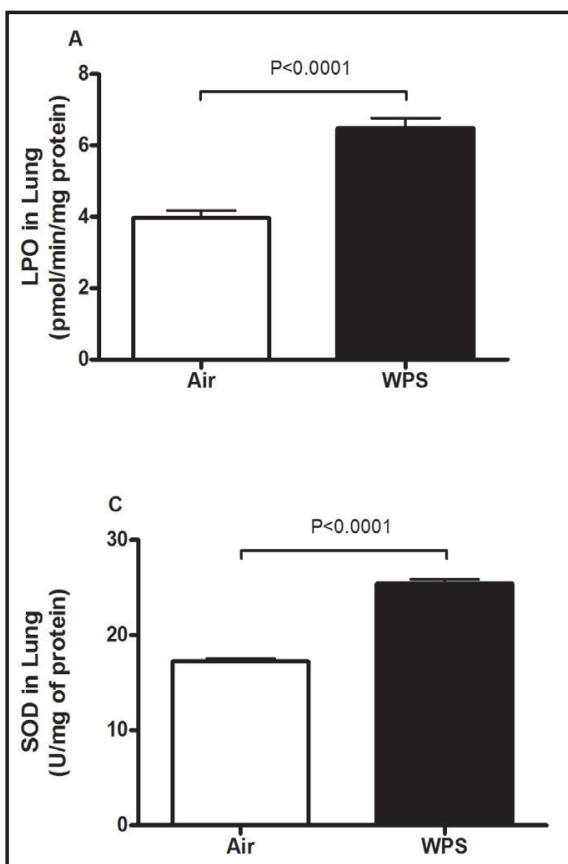
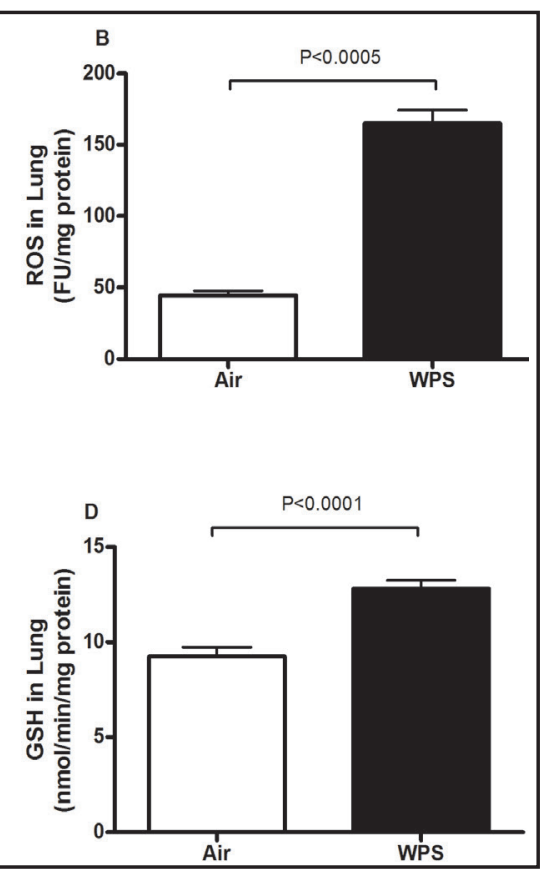

Fig. 7. DNA migration ( $\mathrm{mm}$ ) in the lung tissues assessed by Comet assay at the end of the six-month exposure period to air (control) or water pipe smoking (WPS). Data are mean \pm SEM $(n=5)$.

\section{Lung DNA damage}

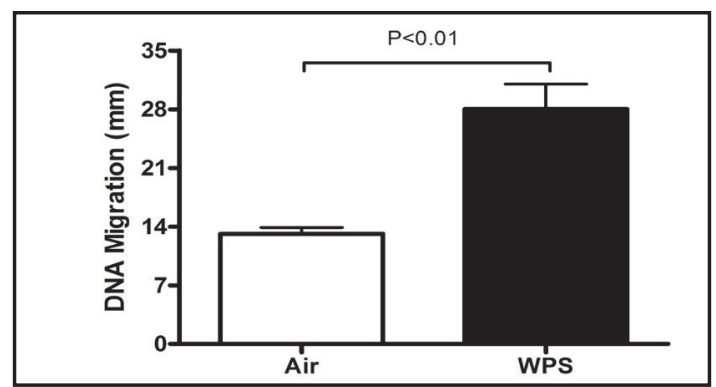

Figure 7 illustrates the effect of chronic exposure to WPS on lung DNA damage. Compared with control group, nose-only WPS exposure caused a significant increase of DNA migration $(\mathrm{P}<0.01)$.

\section{Airway hyper-reactivity to methacholine}

Figure 8A shows airway resistance, measured by the forced oscillations technique after increasing concentrations of methacholine $(0-40 \mathrm{mg} / \mathrm{ml})$, following nose-only exposure to air or WPS for six months. In comparison to air-exposed mice, WPS exposure caused a dose dependent increase in airway resistance. From the resistance methacholine doseresponse curve, an index of airway responsiveness was calculated as the slope of the linear regression using $0-40 \mathrm{mg} / \mathrm{ml}$ concentration. The latter showed a significant increase of airway resistance in WPS-exposed mice compared to air-exposed ones $(\mathrm{P}<0.01$, Fig. 8B).

\section{Discussion}

The present study showed that chronic (six months) nose-only exposure to WPS increased airway resistance and induced pulmonary inflammation as evidenced by influx of neutrophils and lymphocytes, and increase of LDH, MPO, MMP9, TNF $\alpha$, IL-6 and IL1 $\beta$ in BALF. Histopathological analysis of lung tissues after WPS exposure revealed the presence of dilated alveolar spaces and alveolar ducts with damaged interalveolar septae, and foci of mixed inflammatory cells infiltration in the interalveolar interstitium which consisted mainly in neutrophils, lymphocytes and macrophages. Moreover, six month WPS exposure caused oxidative stress and DNA damage of the lung.

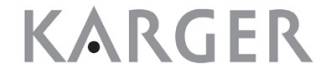




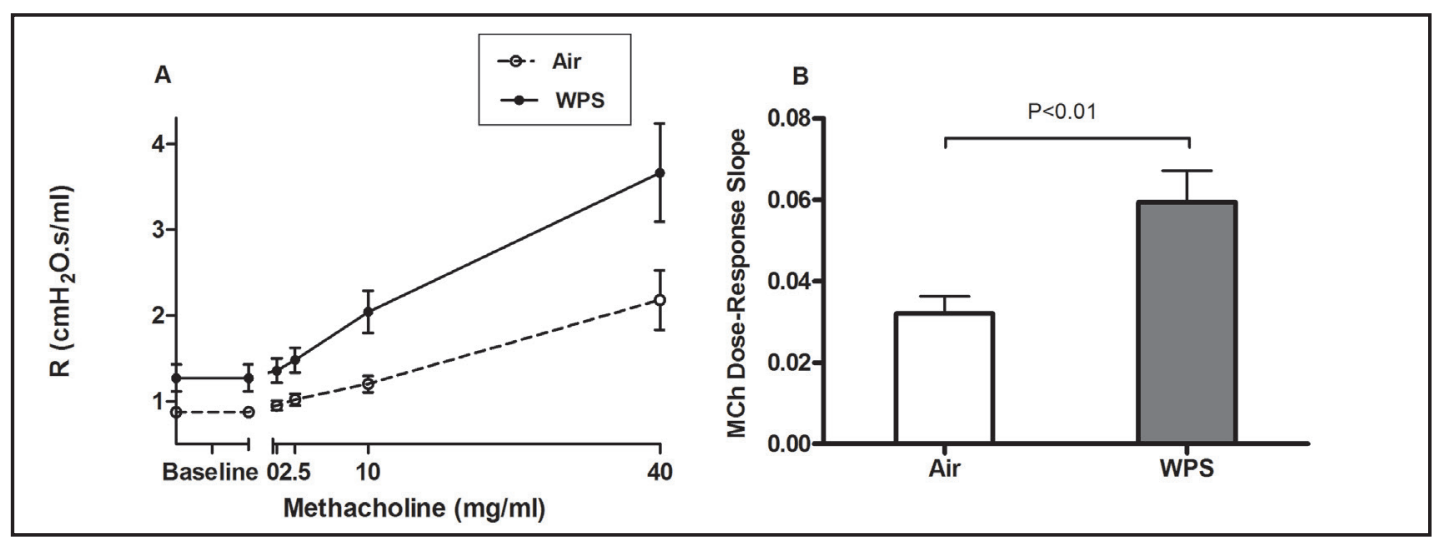

Fig. 8. Airway responsiveness to methacholine (MCh). The airway resistance $(R)$, after increasing concentrations of MCh (0 - $40 \mathrm{mg} / \mathrm{ml})$, was measured via the forced oscillation technique (FlexiVent) at the end of the six-month exposure period to air (control) or water pipe smoking (WPS). Dose-response relationship of total respiratory system resistance to increasing doses of $\mathrm{MCh}(\mathrm{A})$. From the resistance $\mathrm{MCh}$ dose-response curve in (A), an index of airway responsiveness was calculated as the slope of the linear regression using $0-40 \mathrm{mg} / \mathrm{ml}$ doses (B). Data are mean \pm SEM $(\mathrm{n}=8)$.

Although some epidemiological studies reported association between WPS and COPD $[11,12]$, experimental evidence on the chronic effects of WPS is lacking. We have recently demonstrated that 1-month nose-only WPS exposure causes lung inflammation and oxidative stress, and increased airway resistance in mice [15]. In a subsequent study, we showed that early (5-days) exposure to WPS cause caused pulmonary inflammation and oxidative stress without affecting airway resistance suggesting that inflammation and oxidative stress are early markers of WPS exposure that precedes airway dysfunction. [13]. In the present study, we wanted to verify the persistence of pulmonary inflammation and oxidative stress in mice chronically-exposed (six months) to WPS and to assess, for the first time, its effect on alveolar injury and DNA damage and their association with impairment of lung function.

Our data show that six months exposure to WPS causes influx of neutrophils and lymphocytes in the lung. We and others have reported an increase in neutrophils and lymphocytes following acute and 1 month WPS exposure [13-15]. Similar observations have been reported in mice exposed six months to CS with a nose-only exposure system [26]. Neutrophils are the most abundant inflammatory cells present in the bronchial wall and lumen of patients with COPD [31]. We also found a significant increase of MPO and MMP9 in BALF following chronic exposure to WPS. MPO is found in azurophilic granules of neutrophils, and its content is increased in smokers [31, 32]. MPO can induce oxidative stress and inflammation following CS exposure [31]. Together with other MMPs, MMP9 can induce extracellular matrix destruction, comprising collagen, laminin, and gelatin, thus enabling neutrophil extravasation and migration [31]. MMP9 has been linked to parenchymal pulmonary destruction, neutrophilia and decrease in lung function in emphysema [33]. We also found a significant increase of proinflammatory cytokines including TNF $\alpha$, IL-6 and IL1 $\beta$ in BALF. The latter could be explained, at least partly, by the neutrophilic inflammation and the release of MPO. Indeed, there is substantiation that MPO, can directly up-regulate the inflammatory reaction [31]. It has been demonstrated that MPO can induce TNF $\alpha$ release from macrophages and activate neutrophils causing their degranulation, and that MPO internalized by endothelial cells provokes the release of IL-6, IL-8, and ROS [34]. Moreover, it has been reported that that TNF- $\alpha$ drives the majority of cigarette smoke-related emphysema in the mouse [35], and that serum TNF $\alpha$ and IL1 $\beta$ were higher in active smokers compared with non-smokers [36].

The inflammatory response to CS plays a key role is in the pathogenesis of COPD, and even after smoking cessation an unremitting cycle of inflammation leads to a sustained decrease in pulmonary function [31, 37]. Similarly, chronic exposure to CS causes alveolar 


\section{Cellular Physiology Cell Physiol Biochem 2016;38:982-992 \\ and Biochemistry Published online: March 04, $2016 \quad$\begin{tabular}{l|l} 
DOI: 2016 The Author(s). Published by S. Karger AG, Basel \\
www.karger.com/cpb
\end{tabular} \\ Nemmar et al.: Chronic Respiratory Effects of Water-Pipe Smoking in Mice}

destruction and airspace enlargement leading to emphysema [26, 38]. Nevertheless, as far as we are aware, no experimental study, so far, has investigated the effect of chronic exposure to WPS on alveolar injury. Our data show, for the first time, that chronic exposure to WPS causes dilatation of alveolar spaces and alveolar ducts with damaged interalveolar septae. The mean diameters of the alveolar spaces and ducts, measured using Olympus DP71 camera and software, were significantly increased in WPS-exposed mice. Epidemiological studies reported difficulties in studying the isolated effects of WPS because most of the smokers are also current or past cigarette smokers. Nevertheless, two studies established the association between WPS and COPD after adjusting for possible confounders such as age and CS $[11,12]$. Therefore, our findings give biological plausibility to these epidemiological studies.

It is well established that tobacco smoke contains many oxidants and free radicals, and inhalation of tobacco smoke into the lung also induce the activation of neutrophils and macrophages, which aggravate the oxidative stress [39]. Both oxidative injury and pulmonary inflammation form a vicious cycle that is leads to disease progression in patients with COPD [31]. To further assess the mechanism behind the chronic exposure to WPS, we measured several markers of oxidative stress in the lung tissue. Our data show that WPS exposure causes a significant increase in ROS and LPO concentrations in lung tissue. We have recently reported an increase in lipid peroxidation in lung tissues and ROS at the end of 5 -days and one month exposure to WPS $[13,15]$. Moreover, here, we have also measured the concentration of GSH, a free radical scavenger, and a major antioxidant enzyme, i.e. SOD. Our data show a significant increase of both GSH and SOD following chronic exposure to WPS. An increase of antioxidants indicates that the development of oxidative stress is accompanied by an adaptive response that counterbalances the potentially damaging activity of oxygen free radicals by antioxidant defense mechanisms [40]. An increase of antioxidants has been reported after exposure to CS and lipopolysaccharides exposure in mice [40].

Oxidative stress results from an imbalance between radical-generating and radicalscavenging systems leading to cell membrane impairment or DNA damage [41]. Our data show that chronic exposure to WPS cause lung DNA damage. Such effect has never been reported before. These findings suggest that WPS induced DNA damage by promoting a milieu of oxidative stress and inflammation [42]. Such genotoxicity and cellular changes may lead to cancer [42]. Previous studies have showed that water-pipe smokers had more chromosomal aberrations, augmented sister chromatid exchanges in lymphocytes and higher micronuclei in buccal mucosa cells [43]. Experimental study in rats reported the occurrence of DNA alterations after chronic exposure to CS (1 h/day, 5 days/week for 8 months) [44].

Along with pulmonary inflammation, oxidative stress, DNA damage and alveolar injury, we show that six months exposure to WPS causes alteration of lung function evidenced by a significant increase in airway resistance in WPS-exposed mice compared to control group. Using whole body plethysmograph, it has been recently demonstrated that chronic noseonly CS exposure cause a significant 31-37\% increase in total lung capacity and a significant 26-35\% increase in compliance when compared with animals exposed to air only [26].

In conclusion, we demonstrate the persistence of lung inflammation and oxidative stress in mice chronically exposed to WPS and show, for the first time, the occurrence of DNA damage and enlargement of alveolar spaces and ducts associated with impairment of lung function. Our findings provide novel evidence on the long-term effects of exposure to WPS. Our results provide a plausible mechanistic explanation for the limited epidemiological and clinical studies describing the adverse respiratory effects of chronic exposure to WPS.

\section{Acknowledgments}

This work was supported by funds of the College of Medicine and Health Sciences grant (31M215), and United Arab Emirates University UPAR (31M189) and center-based interdisciplinary (31R052) grants. 


\section{Cellular Physiology Cell Physiol Biochem 2016;38:982-992

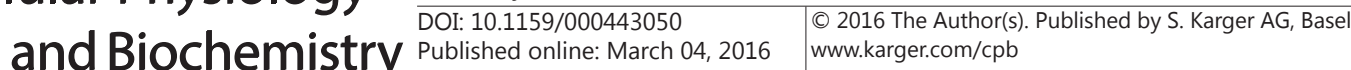 \\ Nemmar et al.: Chronic Respiratory Effects of Water-Pipe Smoking in Mice}

\section{Disclosure Statement}

No conflicts of interest, financial or otherwise, are declared by the author(s).

\section{References}

1 World Health Organization: WHO Report on the Global Tobacco Epidemic, 2011. World Health Organization 2011.

2 Jackson D, Aveyard P: Waterpipe smoking in students: prevalence, risk factors, symptoms of addiction, and smoke intake. Evidence from one British university. BMC Public Health 2008;8:174.

3 Chaouachi K: Hookah (Shisha, Narghile) Smoking and Environmental Tobacco Smoke (ETS). A critical review of the relevant literature and the public health consequences. Int J Environ Res Public Health 2009;6:798-843.

4 Eissenberg T, Shihadeh A: Waterpipe tobacco and cigarette smoking: direct comparison of toxicant exposure. Am J Prev Med 2009;37:518-523.

5 Maziak W: The global epidemic of waterpipe smoking. Addict Behav 2011;36:1-5.

6 ESC Press Office.: Rapid urbanization as well as cultural habits explain the rise in heart disease in the Gulf States. Eur Heart J 2012;33:1291.

7 Jensen PD, Cortes R, Engholm G, Kremers S, Gislum M: Waterpipe use predicts progression to regular cigarette smoking among Danish youth. Subst Use Misuse 2010;45:1245-1261.

8 Knishkowy B, Amitai Y: Water-pipe (narghile) smoking: an emerging health risk behavior. Pediatrics 2005;116:e113-e119.

9 Boskabady MH, Farhang L, Mahmodinia M, Boskabady M, Heydari GR: Comparison of pulmonary function and respiratory symptoms in water pipe and cigarette smokers. Respirology 2012;17:950-956.

10 Raad D, Gaddam S, Schunemann HJ, Irani J, Abou JP, Honeine R, Akl EA: Effects of water-pipe smoking on lung function: a systematic review and meta-analysis. Chest 2011;139:764-774.

11 She J, Yang P, Wang Y, Qin X, Fan J, Wang Y, Gao G, Luo G, Ma K, Li B, Li C, Wang X, Song Y, Bai C: Chinese water-pipe smoking and the risk of COPD. Chest 2014;146:924-931.

12 Waked M, Khayat G, Salameh P: Chronic obstructive pulmonary disease prevalence in Lebanon: a crosssectional descriptive study. Clin Epidemiol 2011;3:315-323.

13 Nemmar A, Al HA, Al HN, Yuvaraju P, Beegam S, Yasin J, Elwasila M, Ali BH, Adeghate E: Early pulmonary events of nose-only water pipe (shisha) smoking exposure in mice. Physiol Rep 2015;3.

14 Khabour OF, Alzoubi KH, Bani-Ahmad M, Dodin A, Eissenberg T, Shihadeh A: Acute exposure to waterpipe tobacco smoke induces changes in the oxidative and inflammatory markers in mouse lung. Inhal Toxicol 2012;24:667-675.

15 Nemmar A, Raza H, Yuvaraju P, Beegam S, John A, Yasin J, Hameed RS, Adeghate E, Ali BH: Nose-only water-pipe smoking effects on airway resistance, inflammation and oxidative stress in mice. J Appl Physiol 2013;115:1316-1323.

16 Nemmar A, Raza H, Subramaniyan D, Yasin J, John A, Ali BH, Kazzam EE: Short-Term Systemic Effects of Nose-Only Cigarette Smoke Exposure in Mice: Role of Oxidative Stress. Cell Physiol Biochem 2013;31:1524.

17 Nemmar A, Yuvaraju P, Beegam S, Ali BH: Short-term nose-only water-pipe (shisha) smoking exposure accelerates coagulation and causes cardiac inflammation and oxidative stress in mice. Cell Physiol Biochem 2015;35:829-840.

18 Raza H, John A, Nemmar A: Short-term effects of nose-only cigarette smoke exposure on glutathione redox homeostasis, cytochrome P450 1A1/2 and respiratory enzyme activities in mice tissues. Cell Physiol Biochem 2013;31:683-692.

19 Nemmar A, Yuvaraju P, Beegam S, John A, Raza H, Ali BH: Cardiovascular effects of nose-only water-pipe smoking exposure in mice. Am J Physiol Heart Circ Physiol 2013;305:H740-H746.

20 Ali BH, Adham SA, Al Balushi KA, Shalaby A, Waly MI, Manoj P, Beegam S, Yuvaraju P, Nemmar A: Reproductive toxicity to male mice of nose only exposure to water- pipe smoke. Cell Physiol Biochem 2015;35:29-37.

21 Hakim F, Hellou E, Goldbart A, Katz R, Bentur Y, Bentur L: The acute effects of water-pipe smoking on the cardiorespiratory system. Chest 2011;139:775-781.

22 Nemmar A, Dhanasekaran S, Yasin J, Ba-Omar H, Fahim MA, Kazzam EE, Ali BH: Evaluation of the direct 


\section{Cellular Physiology Cell Physiol Biochem 2016;38:982-992

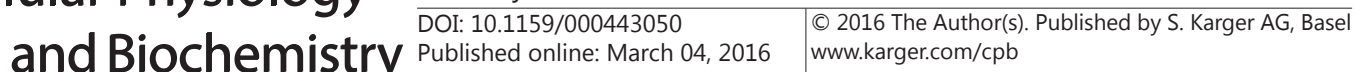 \\ Nemmar et al.: Chronic Respiratory Effects of Water-Pipe Smoking in Mice}

systemic and cardiopulmonary effects of diesel particles in spontaneously hypertensive rats. Toxicology 2009;262:50-56.

23 Nemmar A, Al-Salam S, Zia S, Marzouqi F, Al-Dhaheri A, Subramaniyan D, Dhanasekaran S, Yasin J, Ali BH, Kazzam EE: Contrasting actions of diesel exhaust particles on the pulmonary and cardiovascular systems and the effects of thymoquinone. Br J Pharmacol 2011;164:1871-1882.

24 Nemmar A, Subramaniyan D, Zia S, Yasin J, Ali BH: Airway resistance, inflammation and oxidative stress following exposure to diesel exhaust particle in angiotensin II-induced hypertension in mice. Toxicology 2012;292:162-168.

25 Hardy RD, Coalson JJ, Peters J, Chaparro A, Techasaensiri C, Cantwell AM, Kannan TR, Baseman JB, Dube PH: Analysis of pulmonary inflammation and function in the mouse and baboon after exposure to Mycoplasma pneumoniae CARDS toxin. PLoS One 2009;4:e7562.

26 Rinaldi M, Maes K, De Vleeschauwer S., Thomas D, Verbeken EK, Decramer M, Janssens W, Gayan-Ramirez GN: Long-term nose-only cigarette smoke exposure induces emphysema and mild skeletal muscle dysfunction in mice. Dis Model Mech 2012;5:333-341.

27 de Souza MF, Goncales TA, Steinmetz A, Moura DJ, Saffi J, Gomez R, Barros HM: Cocaine induces DNA damage in distinct brain areas of female rats under different hormonal conditions. Clin Exp Pharmacol Physiol 2014;41:265-269.

28 Olive PL, Banath JP, Fjell CD: DNA strand breakage and DNA structure influence staining with propidium iodide using the alkaline comet assay. Cytometry 1994;16:305-312.

29 Hartmann A, Speit G: The contribution of cytotoxicity to DNA-effects in the single cell gel test (comet assay). Toxicol Lett 1997;90:183-188.

30 Nemmar A, Al-Salam S, Subramaniyan D, Yasin J, Yuvaraju P, Beegam S, Ali BH: Influence of experimental type 1 diabetes on the pulmonary effects of diesel exhaust particles in mice. Toxicol Lett 2012.

31 Hoenderdos K, Condliffe A: The neutrophil in chronic obstructive pulmonary disease. Am J Respir Cell Mol Biol 2013;48:531-539.

32 Bridges RB, Fu MC, Rehm SR: Increased neutrophil myeloperoxidase activity associated with cigarette smoking. Eur J Respir Dis 1985;67:84-93.

33 Finlay GA, Russell KJ, McMahon KJ, D’arcy EM, Masterson JB, FitzGerald MX, O’Connor CM: Elevated levels of matrix metalloproteinases in bronchoalveolar lavage fluid of emphysematous patients. Thorax 1997;52:502-506.

34 Lefkowitz DL, Roberts E, Grattendick K, Schwab C, Stuart R, Lincoln J, Allen RC, Moguilevsky N, Bollen A, Lefkowitz SS: The endothelium and cytokine secretion: the role of peroxidases as immunoregulators. Cell Immunol 2000;202:23-30.

35 Churg A, Wang RD, Tai H, Wang X, Xie C, Wright JL: Tumor necrosis factor-alpha drives 70\% of cigarette smoke-induced emphysema in the mouse. Am J Respir Crit Care Med 2004;170:492-498.

36 Barbieri SS, Zacchi E, Amadio P, Gianellini S, Mussoni L, Weksler BB, Tremoli E: Cytokines present in smokers' serum interact with smoke components to enhance endothelial dysfunction. Cardiovasc Res 2011;90:475-483.

37 World Health Organization: Chronic obstructive pulmonary disease (COPD). WHO 2012; Fact sheet $\mathrm{N}^{\circ} 315$.

38 Toledo AC, Magalhaes RM, Hizume DC, Vieira RP, Biselli PJ, Moriya HT, Mauad T, Lopes FD, Martins MA: Aerobic exercise attenuates pulmonary injury induced by exposure to cigarette smoke. Eur Respir J 2012;39:254-264.

39 Birben E, Sahiner UM, Sackesen C, Erzurum S, Kalayci O: Oxidative stress and antioxidant defense. World Allergy Organ J 2012;5:9-19.

40 Valenca SS, Silva BF, Lopes AA, Romana-Souza B, Marinho Cavalcante MC, Lima AB, Goncalves K, V, Porto LC: Oxidative stress in mouse plasma and lungs induced by cigarette smoke and lipopolysaccharide. Environ Res 2008;108:199-204.

41 Yao H, Rahman I: Current concepts on oxidative/carbonyl stress, inflammation and epigenetics in pathogenesis of chronic obstructive pulmonary disease. Toxicol Appl Pharmacol 2011;254:72-85.

42 Moller P, Danielsen PH, Karottki DG, Jantzen K, Roursgaard M, Klingberg H, Jensen DM, Christophersen DV, Hemmingsen JG, Cao Y, Loft S: Oxidative stress and inflammation generated DNA damage by exposure to air pollution particles. Mutat Res Rev Mutat Res 2014;762:133-166.

43 El-Zaatari ZM, Chami HA, Zaatari GS: Health effects associated with waterpipe smoking. Tob Control 2015;24 Suppl 1:i31-i43.

44 Izzotti A, Balansky RM, Blagoeva PM, Mircheva ZI, Tulimiero L, Cartiglia C, De FS: DNA alterations in rat organs after chronic exposure to cigarette smoke and/or ethanol ingestion. FASEB J 1998;12:753-758. 